\title{
Nesting Ecology of West African Dwarf Crocodiles in a Heavily Disturbed Landscape in Chirehin, Ghana
}

\author{
Emmanuel Amoah (D), ${ }^{1,2}$ Emmanuel Danquah, ${ }^{1}$ and James Perran Ross ${ }^{3}$ \\ ${ }^{1}$ Department of Wildife and Range Management, Kwame Nkrumah University of Science and Technology, Kumasi, Ghana \\ ${ }^{2}$ Threatened Species Conservation Alliance, P.O. Box UP 1642, Kumasi, Ghana \\ ${ }^{3}$ Department of Wildlife Ecology and Conservation, University of Florida, Gainesville, FL 32601, USA
}

Correspondence should be addressed to Emmanuel Amoah; emmanuelamoah610@gmail.com

Received 7 August 2020; Revised 1 March 2021; Accepted 26 May 2021; Published 8 June 2021

Academic Editor: Ram Chander Sihag

Copyright (C) 2021 Emmanuel Amoah et al. This is an open access article distributed under the Creative Commons Attribution License, which permits unrestricted use, distribution, and reproduction in any medium, provided the original work is properly cited.

\begin{abstract}
West African dwarf crocodiles (Osteolaemus sp. nov. cf. tetraspis) are among the most threatened crocodilians in the world due to unregulated hunting and habitat loss-related population decline. Despite this, many questions about their basic ecology remain unanswered and this inadequate data hampers effective dwarf crocodile management. We describe incubation temperature, nesting success, hatching rate, and clutch size of West African dwarf crocodiles. We monitored 18 nests from the 2017 and 2018 nesting seasons in the Chirehin Community Land-a highly disturbed agricultural matrix in the climatic transition zone of Ghana. We used Hobo tidbit ${ }^{\circledR}$ data loggers to monitor egg chamber temperature and the effect of ambient temperature on nest temperature. The daily mean incubation temperature recorded during the study was $30.7^{\circ} \mathrm{C}\left( \pm \mathrm{SD}=0.8^{\circ} \mathrm{C}, n=240\right.$, range $=28-33^{\circ} \mathrm{C}$ ) and it is congruent with the reported value for the species. The findings from this study suggest a weak positive to no correlation between dwarf crocodile incubation temperature and ambient temperature indicating nest temperature is almost independent of ambient temperature. We found a mean clutch size of 8 eggs per nest $(\mathrm{SD}= \pm 2$; range $=5-13 ; n=17)$ supporting previous reports that this genus has a low clutch size. The mean nesting success and hatching success across the two seasons were $77.8 \%$ and $75.3 \%(\mathrm{SD}= \pm 41.9, n=18)$, respectively. Three nests were destroyed by flood and one by an unknown predator suspected to be a West African Nile monitor lizard. Generally, dwarf crocodiles selected forest patches within the highly disturbed landscape for nesting indicating the need to protect the remaining forest patches. Efforts should be made to repeat the study across this species' range for an improved understanding of its nesting ecology.
\end{abstract}

\section{Introduction}

African dwarf crocodiles (genus Osteolaemus) are relatively small, secretive, and docile crocodilians that are endemic to western Africa from the Democratic Republic of Congo to The Gambia $[1,2]$. African dwarf crocodiles typically inhabit forest streams, isolated pools, and swamps where access to sunlight is limited [3-7]. Throughout its range, African dwarf crocodiles are experiencing rapid population declines due to unregulated harvesting for food and habitat destruction often for agricultural purposes $[6,8,9]$. Dwarf crocodiles are categorized as vulnerable on the IUCN Red List [10] and all populations are on Appendix I of the Convention on International Trade in Endangered Species
(CITES) checklist [11]. However, an update of the Red List status may be necessary following the taxonomy revision by Eaton et al. [8] that recognized three lineages in the genus Osteolaemus, namely, Osteolaemus osborni restricted to the Congo Basin, Osteolaemus tetraspis found in the Lower Guinea bioregion of west Central Africa and yet to be named Osteolaemus sp. nov. cf. tetraspis distributed in the Upper Guinea bioregion of West Africa. Splitting of the already depleted population of African dwarf crocodiles into three distinctive biogeographic populations implies that the respective populations are at higher risk of extinction than previously known.

Despite its threatened status, dwarf crocodiles are still among the least studied crocodilians in the world [2]. For the 
past three decades, there have been a handful of studies on the basic ecology of wild populations of dwarf crocodiles in West Africa $[3,6,7,9]$. Among the key reasons given for this paucity of research are secluded habitats of the species which severely affects field observations, low population densities, the low interest of the skin industry [7], and lack of local expertise in most parts of West Africa. This dearth of knowledge coupled with increasing anthropogenic related threats warrants research on all aspects of dwarf crocodile ecology to aid evidence-based management decisions.

One of the fundamentals to consider when developing effective conservation strategies for endangered crocodilians is their reproductive ecology $[12,13]$. Unfortunately, very little has been published on the nesting ecology of wild populations of West African dwarf crocodiles. The most recent official studies on the nesting ecology of West African dwarf crocodiles were conducted over 30 years ago in the tropical rainforest of Tai National Park in Côte d'Ivoire [7]. Sparse information available suggests dwarf crocodiles are mound nesters that use dead leaves and rotten vegetation for nest construction at the beginning of the raining season (late March) and the nesting season continues till the end of November. The reported mean clutch size and incubation days from the wild are 10 eggs $(\mathrm{SD}= \pm 4 ; n=4)$ and 100 days $(\mathrm{SD}= \pm 10 ; n=4)$, respectively [7]. Waitkuwait [7] further reported that incubation temperature within dwarf crocodile nest ranged between 26 and $34^{\circ} \mathrm{C}$. The current study aims at adding to the existing knowledge on the nesting ecology of West African dwarf crocodiles. So, we investigated the incubation temperature, nesting success, hatching success, incubation days, and clutch size of West African dwarf crocodiles (Osteolaemus sp. nov. cf. tetraspis).

\section{Materials and Methods}

2.1. Study Area. This study was conducted in Nimprun Stream located in the Chirehin Community Land. This parcel of land is located in the Bono East Region of Ghana $\left(7^{\circ} 51^{\prime} 30^{\prime \prime} \mathrm{N}-7^{\circ} 53^{\prime} 0^{\prime \prime} \mathrm{N} ; 1^{\circ} 41^{\prime} 30^{\prime \prime} \mathrm{W}-1^{\circ} 43^{\prime} 0^{\prime \prime} \mathrm{W}\right)$ about $2.5 \mathrm{~km}$ from Jema, the Kintampo South District capital. The area is located in the transition zone of Ghana between the southern forest zone and the northern savannah zone. The district experiences an interior savannah type of climate, a modified form of the wet-semiequatorial type of climate. The mean annual rainfall is between $1,400 \mathrm{~mm}$ and $1800 \mathrm{~mm}$ and occurs in two seasons; from May to July and from September to October. The mean annual temperature ranges from $26.5^{\circ} \mathrm{C}$ to $27.2^{\circ} \mathrm{C}$ with minimum and maximum mean monthly temperature of $24^{\circ} \mathrm{C}$ and $30^{\circ} \mathrm{C}$, respectively [14].

The Chirehin Community Land was selected over other known habitats of dwarf crocodiles in Ghana because it harbours the most abundant known population in Ghana (E. Amoah pers. obs.). This makes it a viable location for conducting detailed studies on the breeding ecology of this rare species. The Nimprun Stream is located about $1.2 \mathrm{~km}$ from the Chirehin village which has a human population of a little over three hundred (300). The stream is deeply embedded in local culture and all its aquatic creatures, including dwarf crocodiles, have benefitted from traditional beliefs that strictly prohibit their consumption. The stream has an average width of about $2 \mathrm{~m}$. The vegetation consists of raffia palm, guinea grass, and sage weed which are sparsely interspersed with small forest patches that rarely exceed one acre. Most portions of the stream catchment are watersaturated and very challenging to walk through especially during the wet seasons. The main land-use activity identified around the catchment of Nimprun Stream is farming. The major crops grown in the area include cashew, maize, yam, and pepper. People have encroached on most parts of the stream bank and there is virtually no buffer left around the stream (Figure 1).

2.2. Data Collection and Analyses. We thoroughly searched the banks of Nimprun Stream for West African dwarf crocodile nests during the 2017 and 2018 nesting seasons (late March-August). Once an active nest was located, we carefully opened it. Eggs in situ were marked with pencil on the dorsal surface and their original orientation was maintained as they were removed and counted $[13,15]$. The viability of eggs was determined by the presence of a visible band and since we did not observe females laying eggs, we estimated the date of oviposition based on the extent of banding [16]. We measured the egg mass, egg width, and egg length of three randomly selected nests. Our interest was to compare the clutch attributes to the reported values of Waitkuwait [7] and also assess the relationship between these parameters and clutch size. We weighed eggs with a spring balance to the nearest $0.5 \mathrm{~g}$, and the width and length measured with dial callipers to the nearest $0.1 \mathrm{~mm}$. After taking the clutch data, Hobo tidbits ${ }^{\circledR}$ data logger programmed to record at 30 minutes was placed inside the egg chamber and nests were carefully covered to minimize disturbance $[15,17,18]$. At two of the nests (Nests 2 and 4), the ambient (air) temperature was recorded simultaneously with egg chamber temperature. We suspended a data logger from a tree to hang 1 meter above the nest. The outside loggers were exposed to the external conditions around the nests. We defined hatching success as the percentage of eggs laid that successfully hatched and nesting success as the proportion of nests from which at least one egg hatched, following Platt and Thorbjarnarson [13]. Hatching dates were either obtained from camera traps or estimated from the temperature trend of data loggers placed inside the egg chamber.

We performed descriptive statistics to determine the average clutch size, egg mass, egg length, egg width, and incubation days. We compared the difference of means of egg length, egg width, and egg mass among clutches using the Kruskal-Wallis rank sum test. We examined the relationship between clutch size and egg size using Spearman's rank correlation analyses. We calculated nesting success and hatching rate as 


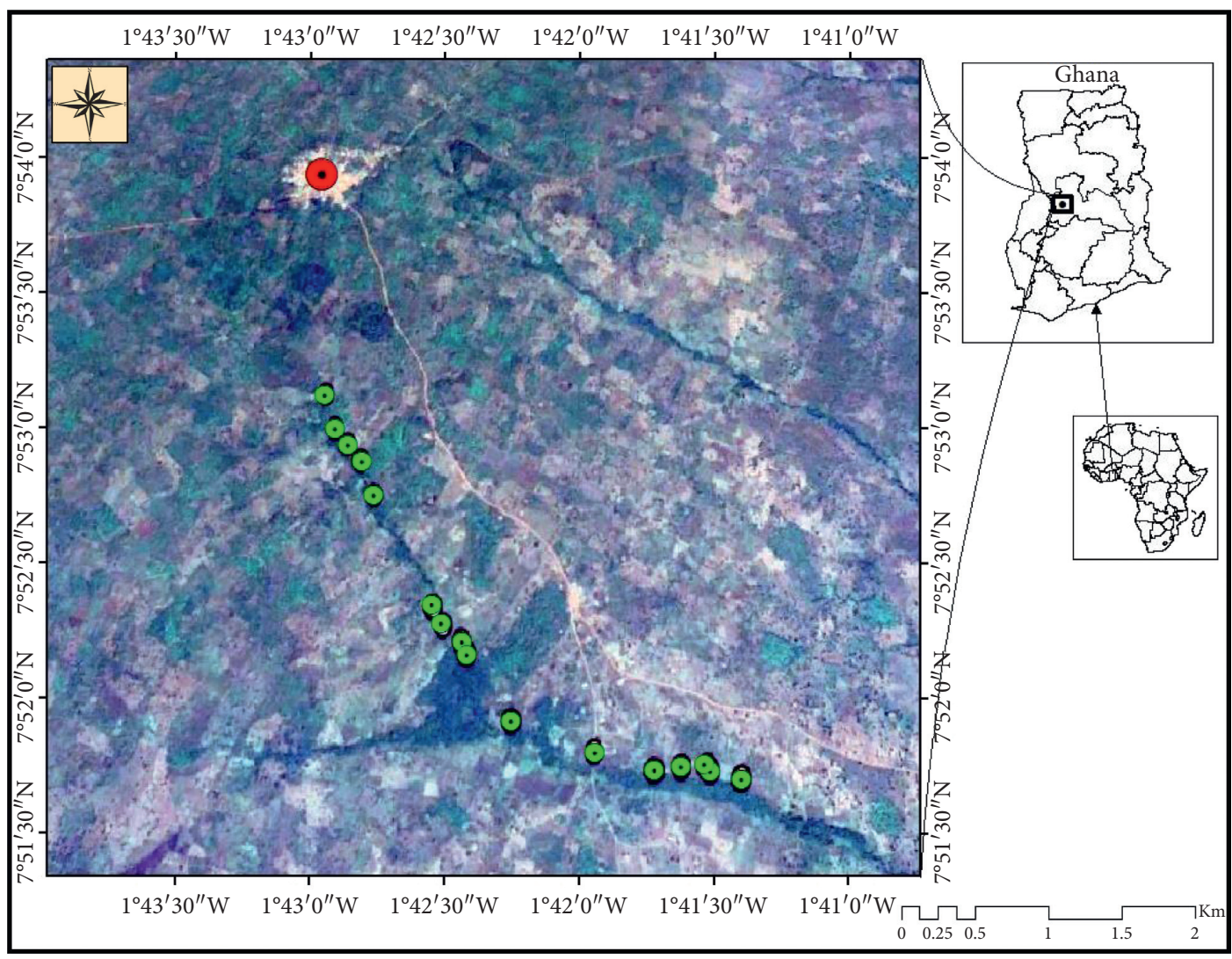

\begin{tabular}{ll}
$\odot$ & Nest location \\
$\odot$ & Cherehin community \\
\hline & Study area
\end{tabular}

Figure 1: Aerial image of Chirehin Community Land. Green circles indicate nest locations.

$$
\begin{aligned}
& \text { nesting success }=\frac{\text { number of nests that had at least one egg hatched }}{\text { total number of nests found }} \times 100, \\
& \quad \text { hatching rate }=\frac{\text { number of eggs hatched }}{\text { total number of eggs found }} \times 100 .
\end{aligned}
$$

Similarly, we performed descriptive statistics on nest incubation temperature and ambient temperature. Spearman's rank correlation was run to assess the relationship between mean daily nest temperature and mean daily ambient temperature. We used the Wilcoxon signed-rank test to compare the mean values of incubation and ambient temperature fluctuations. Graphs of mean daily temperature variations trends and correlations were plotted using Microsoft Excel 2013. Values are expressed as mean, range, and \pm standard deviation.

\section{Results}

3.1. Incubation Temperature in West African Dwarf Crocodile Nests. The daily mean incubation temperature for the three nests had the following descriptive parameters: mean $\left(30.7^{\circ} \mathrm{C} \pm \mathrm{SD}=0.8^{\circ} \mathrm{C}, n=240\right)$, maximum $\left(33^{\circ} \mathrm{C}\right)$, minimum $\left(28^{\circ} \mathrm{C}\right)$, and median $\left(30.7^{\circ} \mathrm{C}\right)$. The individual mean temperature values were the same for nest 3 $\left(31.1^{\circ} \mathrm{C} \pm \mathrm{SD}=0.7, \quad\right.$ range $\left.=30-33^{\circ} \mathrm{C}, \quad n=62\right)$ and nest 4 $\left(31.1^{\circ} \mathrm{C} \pm \mathrm{SD}=0.4\right.$, range $\left.=30-32^{\circ} \mathrm{C}, n=45\right)$ while nest 2 was lower $\left(30^{\circ} \mathrm{C} \pm \mathrm{SD}=0.7^{\circ} \mathrm{C}\right.$, range $\left.=28-32^{\circ} \mathrm{C}, n=89\right)($ Table 1$)$.

The plotted temperature fluxes look similar among the three nests. The plot on the graph ended on different dates because nests were at different stages of development when we found them. As a result, the number of days monitored per nest before hatching occurred varied and loggers were stopped after hatching has occurred (Figure 2).

3.2. The Relationship between Nest Temperature and Ambient Temperature. The ambient and incubation temperatures of nest 2 and nest 4 were measured concurrently to assess the influence of ambient temperature on West African dwarf crocodile incubation temperatures. At nest 2, there was a weak positive correlation between nest incubation 
TABle 1: West African dwarf crocodile incubation temperature $\left({ }^{\circ} \mathrm{C}\right)$; SD and $\mathrm{N}$ represent standard deviations and the total number of recordings used for the calculations, respectively. Differences in $\mathrm{N}$ are a result of the difference in the number of days incubation temperature was monitored before hatching occurred and loggers were stopped after hatching occurred.

\begin{tabular}{lcccc}
\hline Nest number & Mean $\left({ }^{\circ} \mathrm{C}\right) \pm \mathrm{SD}$ & Median & Range & $\mathrm{N}$ \\
\hline Nest 2 & $30 \pm 0.7$ & 30 & $28-32$ & 89 \\
Nest 3 & $31.1 \pm 0.7$ & 31 & $28-32$ & 62 \\
Nest 4 & $31.1 \pm 0.4$ & 31 & $30-32$ & 45 \\
\hline
\end{tabular}

temperature and ambient temperature $(S=89016, p$ value $=0.02, r=0.24, n=89$ ) while at nest 4 , there was no correlation between ambient temperature and incubation temperature $(S=15616, p$ value $=0.8514, r=-0.03, n=45)$ (Figures 3 and 4). A Wilcoxon signed-rank test found a significant difference between daily mean nest incubation temperature fluctuations and daily mean ambient temperature fluctuations both at nest $2(\mathrm{~V}=3187, p$ value $=7.214 e-08)$ and nest $4(\mathrm{~V}=943, p$ value $=1.766 e-07)$.

The daily mean temperature for the two nests was $5^{\circ} \mathrm{C}$ higher than the respective ambient temperatures (Table 2).

The ambient temperature variations at both nests 2 and 4 appeared relatively rapid. On the contrary, nest incubation temperatures appeared to be well-buffered. The daily mean temperature within the egg chamber was consistently higher than the ambient temperature (Figures 5 and 6).

3.3. Clutch Attributes, Hatching Success, Incubation Period, and Nesting Success of West Africa Dwarf Crocodiles in Chirehin. Nest construction and oviposition began in late March and continued through early June and hatching occurred in mid-June through to late August. For the two nesting seasons (2017 and 2018), we recorded 18 nests, 8 and 10 in 2017 and 2018, respectively. None of the nests found in 2018 was constructed on an old nest of 2017 . We found nests in small forest patches (typically less than one acre) which form about $30 \%$ of the riparian vegetation. Nests were usually placed against trees including Strephonema pseudocola, Carapa procera, Pseudospondias microcarpa, Hallea ledermanii, and Raffia ssp. The estimated mean incubation period for 2017 was 95 days (range $=89-100$ days, $\mathrm{SD}= \pm 4$, $n=6$ ) and that of 2018 was 98 days (range $=94-110$ days, $\mathrm{SD}= \pm 5, n=9$ ). The overall mean incubation period for the two seasons was 97 days (ranged $89-110$ days, $S D= \pm 5$, $n=15$ ). We did not directly observe females laying eggs so all dates of oviposition from this study were estimated based on the extent of banding of the eggs at the time nests were opened. Although there might be an issue of accuracy of estimation, it was the only option available. Three of the nests were excluded from incubation period analyses because two of them had fully banded eggs so we could not estimate their respective dates of oviposition and the other had all the eggs eaten by an unknown predator with eggshells left on the nest before we found it. Although we did not directly observe nest predation, we suspect the eggs were eaten by the West African Nile Monitor (Varanus stellatus) the only known predator of crocodile eggs encountered at the site during the study. The average clutch sizes for the 2017 and 2018 nesting seasons were 8 eggs $(\mathrm{SD}= \pm 3$, range $=5-13$ eggs, $n=7)$ and 7 eggs $(\mathrm{SD}= \pm 1$, range $=6-8$ eggs, $n=10)$, respectively. The overall mean clutch size was 8 eggs $(\mathrm{SD}= \pm 2$, range $=5-13, n=17)$. In 2017,6 out of the 8 nests that were found hatched successfully while in 2018,8 out of 10 nests hatched giving nesting success of $75 \%$ and $80 \%$, respectively. The overall nesting success was $77.8 \%$ (Table 3). Of the four failed nests, three were destroyed by flood and the other by a predator. We found a total of 55 eggs in 2017 out of which 48 hatched with a mean hatching rate per nest of $72.4 \%(\mathrm{SD}= \pm 44.9, n=8)$. In 2018 , we recorded 73 eggs from ten nests out of which 56 hatched with a mean hatching rate per nest of $77.5 \%(\mathrm{SD}= \pm 41.6, n=10)(\mathrm{Ta}-$ ble 4$)$. The overall mean hatching rate for the two seasons was $75.3 \%$ ( $\mathrm{SD}= \pm 41.9, n=18)$. The mean egg viability per nest for 2017 was $83.9 \%(\mathrm{SD}= \pm 37.3, n=7)$ while that of 2018 was $90 \%(\mathrm{SD}= \pm 31.6, n=10)$ (Table 5$)$. The mean egg viability per nest for the two seasons was $87.5 \%(\mathrm{SD}= \pm 33.1$, $n=17)$.

3.4. Relationship between Clutch Size, Egg Mass, and Egg Size. Mean egg length and width were $69.9 \mathrm{~mm}(\mathrm{SD}= \pm 2.4$, range $=66-74 \mathrm{~mm}, \quad n=28)$ and $38.3 \mathrm{~mm} \quad(\mathrm{SD}= \pm 1.1$, range $=36-40 \mathrm{~mm}, n=28)$, respectively. Mean egg mass was $66.1 \mathrm{~g}(\mathrm{SD}= \pm 4.9 \mathrm{~g}$, range $=50-75, n=28)$ (Table 6). We found no correlation between mean egg size (egg width $x$ egg length) per nest and clutch size $(r=0.06, p=0.96, \mathrm{df}=1)$. However, there was a weak negative relationship between clutch size and mean egg mass per nest $(r=-0.1, p=0.91$, $\mathrm{df}=1$ ) although the relationship was not significant. We found a significant difference in mean egg mass (Kruskal-Wallis chi-squared $=8.5083, \mathrm{df}=2, p$ value $=0.01)$ and mean egg width (Kruskal-Wallis chi-squared $=17.417$, $\mathrm{df}=2, p$ value $=0.0001)$ among nests. However, there was no significant difference in mean egg length among clutches (Kruskal-Wallis chi-squared $=6.1857, \mathrm{df}=2, p$ value $=0.05$ ) . Below is the graphical representation of the differences in mean among the clutches (Figure 7).

\section{Discussion}

4.1. West Africa Dwarf Crocodile Incubation Temperature. Crocodilians have temperature-dependent sex determination (TDS) where incubation temperatures, particularly during a thermosensitive period (TSP), determine the sex of embryos [19-21]. Crocodilians usually incubate their eggs above $27^{\circ} \mathrm{C}$ [22]. The result from this study is consistent with previous studies as the mean incubation temperatures for all the three nests (nest 2: $\sim 30^{\circ} \mathrm{C}$; nest $3: \sim 31^{\circ} \mathrm{C}$; nest $4: \sim 31^{\circ} \mathrm{C}$ ) were consistent with the reported value. At the Elizabeth Snake Park, the dwarf crocodile nest incubation temperature monitored for 112 days produced a temperature range of $22-27^{\circ} \mathrm{C}$ and resulted in the stoppage of embryonic development at early stages in all the eggs further confirming the report of crocodile incubating their egg above $27^{\circ} \mathrm{C}$ [23]. While the current study did not investigate the relationship 


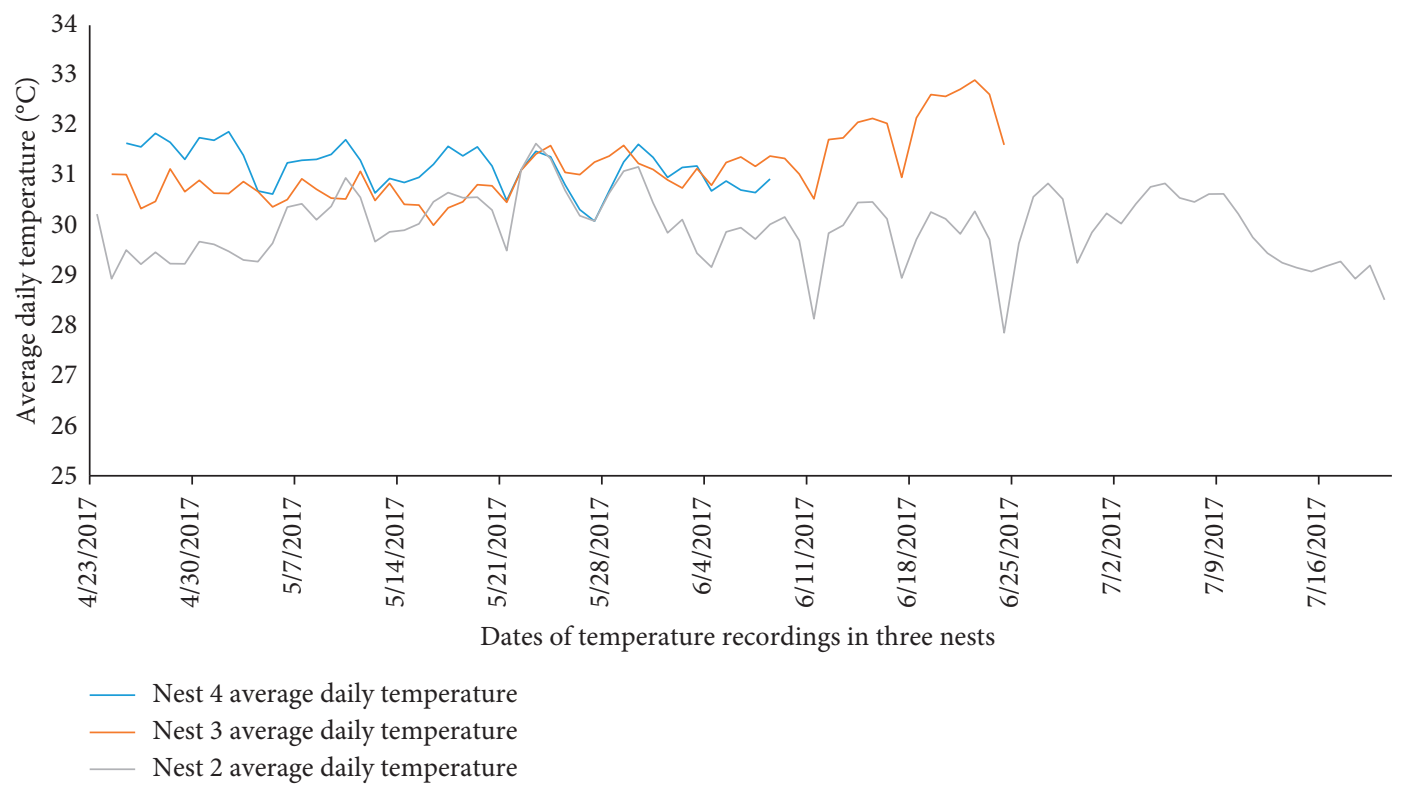

FIGURE 2: Daily mean temperature variation trends in three nests. The plot on the graph ended on different dates because the number of days temperature was monitored was different for each nest.



Figure 3: Correlation of nest 2 mean daily incubation temperature and mean daily ambient temperature.

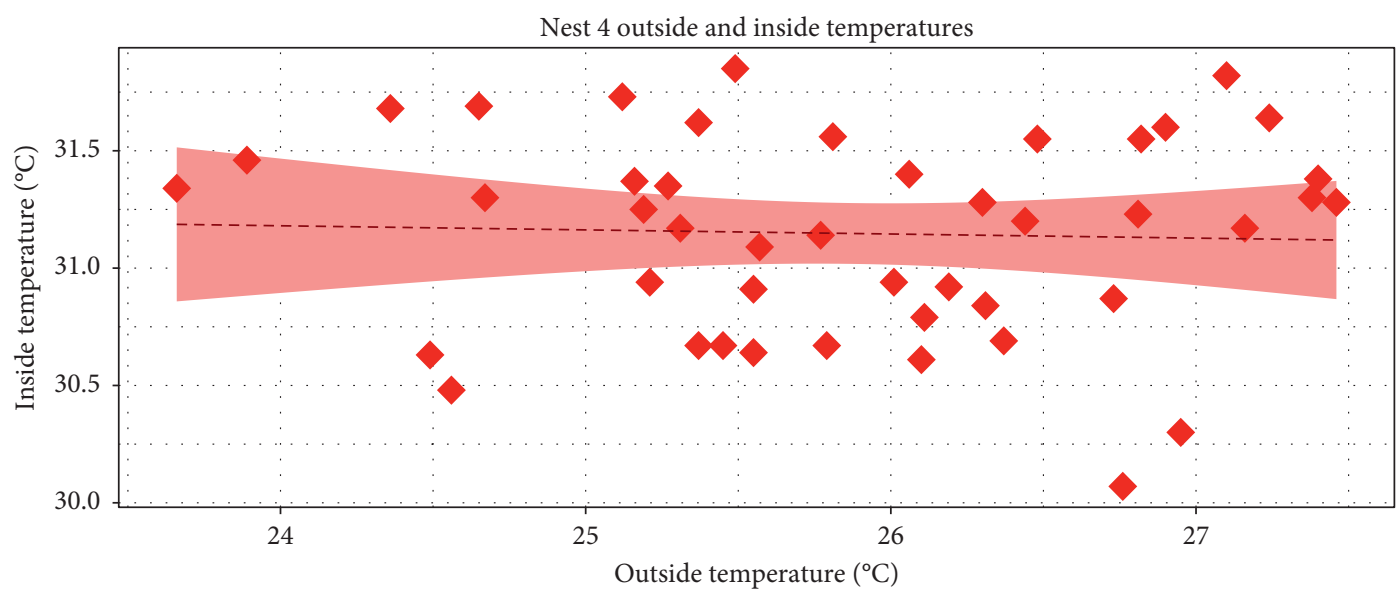

FIgURE 4: Correlation of nest 4 mean daily incubation temperature and mean daily ambient temperature. 
TABle 2: Comparative ranges, means, and respective standard deviations for outside and inside temperature $\left({ }^{\circ} \mathrm{C}\right)$ dynamics of nests.

\begin{tabular}{lccc}
\hline Location & Mean $\left({ }^{\circ} \mathrm{C}\right) \pm \mathrm{SD}$ & Range & $N$ \\
\hline Nest 2 inside & $30 \pm 0.7$ & $28-32$ & 89 \\
Nest 2 outside & $25 \pm 1.3$ & $23-28$ & 89 \\
Nest 4 inside & $31.1 \pm 0.4$ & $30-32$ & 62 \\
Nest 4 outside & $26 \pm 1$ & $24-28$ & 62 \\
\hline
\end{tabular}

between incubation temperature and hatchling sex ratio, data from several species suggest a universal pattern of female-male-female among crocodilians where low (at $31^{\circ} \mathrm{C}$ and below) and high (above $32.5^{\circ} \mathrm{C}$ ) incubation temperatures produce majority females and intermediate incubation temperature $\left(31\right.$ and $\left.32.5^{\circ} \mathrm{C}\right)$ produce majority males $[15,24,25]$. The mean incubation temperature at the thermos-sensitive-period (TSP) was $30.2^{\circ} \mathrm{C}, 30.7^{\circ} \mathrm{C}$, and $31.4^{\circ} \mathrm{C}$ for nest 2 , nest 3 , and nest 4 , respectively. The TSP recorded suggests that nest 2 and nest 3 will produce majority females while nest 4 will produce majority males.

Incubation temperature remains one of the most researched areas in crocodilian biology [24-26]. However, most of these studies have been conducted under laboratory conditions as this allows researchers to easily assess the influence of temperature on sex ratio, hatchling vigour, pigmentation pattern, and hatchling abnormalities [15]. While this approach has increased our understanding of crocodilian incubation temperature and its related issues like sex ratio and hatchling vigour, it does not necessarily represent the true picture of temperature variations in the natural habitat [17]. The average daily incubation temperature patterns observed in all the three nests fluctuated between $28^{\circ} \mathrm{C}$ and $33^{\circ} \mathrm{C}$. Despite this, the temperature remained generally stable in all three nests (Figure 3 ). Several studies [15, 27-29] have shown that wild crocodilian incubation temperature fluctuates and this is influenced by numerous factors including nest material, rainfall regime, environmental temperature, metabolic heat produced by embryo development, vegetation cover, and solar radiation. The temperature range from this study is in line with what was reported by Waitkuwait [7], who also reported a temperature range of $26-34^{\circ} \mathrm{C}$.

Like other crocodilians, dwarf crocodiles have been successfully bred in captivity with various approaches to incubation temperature. While some maintained fixed incubation temperature, others attempted the fluctuating temperature approach. For instance, Tryon [30] successfully bred dwarf crocodile varying temperature between 25 and $34^{\circ} \mathrm{C}$. Helfenderger [31] also conducted a similar study fluctuating the incubation temperature between $27-33^{\circ} \mathrm{C}$. Becks [32], on the contrary, maintained fix temperature of $28^{\circ} \mathrm{C}$ during incubation. Each approach comes with its pros and cons. The result from this study is important for one key reason that is providing the true picture of incubation temperature variation trend in natural nests of West African dwarf crocodiles thereby putting conservationists in a good position to replicate it in captivity for optimal results. This is very important because the species is currently threatened by hunting pressure and habitat disturbances making future captive breeding programmes imminent.

4.2. Relationship between Incubation Temperature and Ambient Temperature of Dwarf Crocodile Nests. The effect of ambient temperature on crocodilian incubation temperatures largely depends on the type of nest. That is, whether it is a hole nest or mound nest. Studies have shown that mound nests are less influenced by ambient temperatures than hole nests $[15,18]$. West African dwarf crocodile is a mound nester which mostly dwells in an environment with reduced insolation [7]. The findings from this study suggest weak positive (nest 2: $S=89016, p$ value $=0.02, r=0.24, n=89$ ) to no correlation (nest 4: $S=15616, p$ value $=0.8514, r=-0.03$, $n=45$ ) between dwarf crocodile incubation temperatures and ambient temperatures indicating nest temperature is almost independent of ambient temperature. We found a significant difference between mean daily incubation temperature fluctuations and ambient temperature fluctuations (nest $2: \mathrm{V}=3187, p$ value $=7.214 e-08$ and nest $4: \mathrm{V}=943, p$ value $=1.766 e-07$ ) further confirming the weak association between the two variables. A similar observation was made by Villamarín-Jurado and Suárez [18] when no relationship was detected between ambient temperature and black caiman (Melanosuchus niger) mound nest incubation temperatures. Waitkuwait [7] conducted a study on West African slender-snouted crocodile (Mecistops cataphractus) which is also a mound nesting crocodile and reported that endogenous heat in conjunction with insulation given by the nest walls creates a largely autonomous microenvironment. The results from this study support previous reports which argued that mound nests have their heat sources and are well-buffered against ambient temperature variations.

\subsection{West African Dwarf Crocodile Clutch Size and Attributes.} In oviparous vertebrates, clutch size is regarded as an important life-history trait and is generally used as a measure of fecundity [33]. The mean clutch value of $\sim 10$ eggs, mean egg size $(\sim 70 \mathrm{~mm} x \sim 38 \mathrm{~mm})$, and mass $(\sim 70 \mathrm{~g})$ of this study are consistent with data published by Waitkuwait [7] on wild populations of West African dwarf crocodile. We found no relationship $(r=0.06, p=0.96, \mathrm{df}=1)$ between mean egg size per nest and clutch size suggesting that there was no trade-off between clutch size and egg size. However, we found a significant difference in mean egg mass among clutches (Kruskal-Wallis chi-squared $=8.5083, \mathrm{df}=2, \quad p$ value $=0.01$ ) suggesting that egg mass varies among clutches. For the two nesting seasons, we never found a nest that was constructed on the previous season's nest. It is possible to detect that a nest has been constructed on an old nest because dwarf crocodiles construct nests with leaf litter which mostly takes more than a year to decompose. It is unclear whether nesting females select different locations every year for nesting or the nesting frequency is once every two years or even less. However, there is evidence of females nesting every year in captivity $[32,34]$. At the Elizabeth Snake Park, an adult female West African dwarf crocodile nested twice within a year laying the first clutch on $3^{\text {rd }}$ March 1986 and 




FIGURE 5: Variation trend of nest 2 ambient temperature and the incubation temperature.

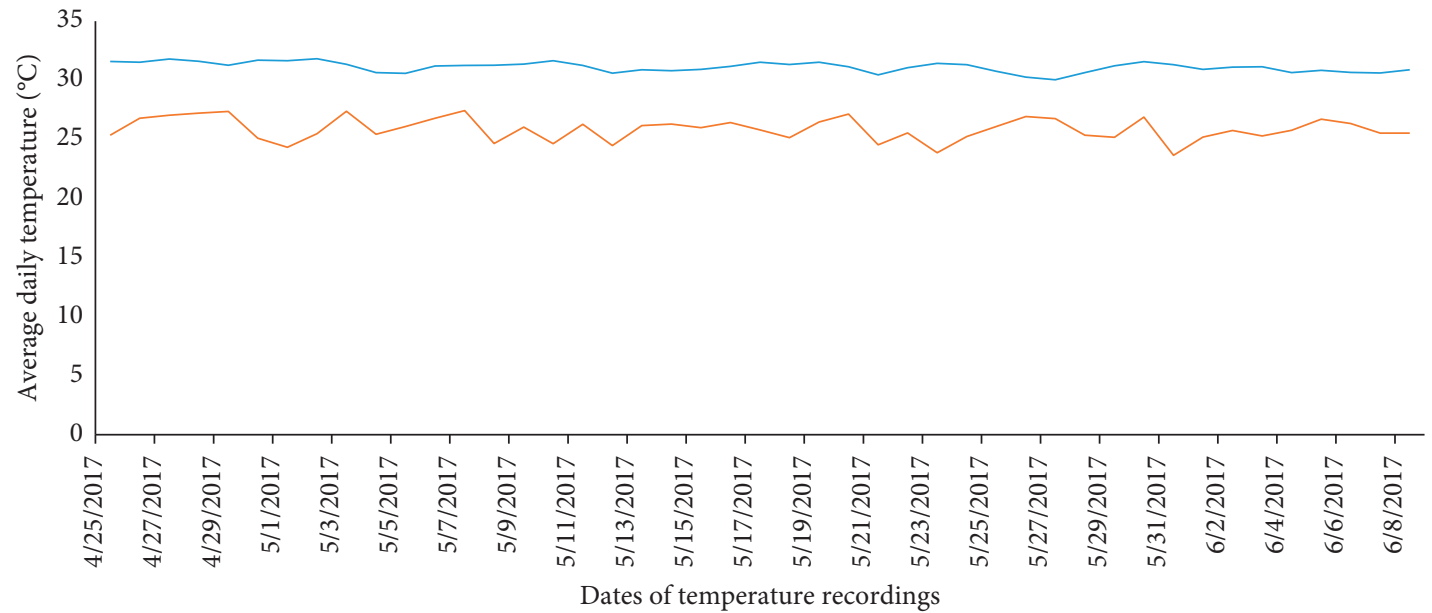

Nest 4 average daily inside temperature

Nest 4 average daily outside temperature

Figure 6: Variation trend of nest 4 ambient temperature and the incubation temperature.

TABLE 3: Fecundity parameters of West African dwarf crocodiles in the Chirehin Community Land, Ghana. SD represents standard deviations and $\mathrm{N}$ the total number of recordings used for the analyses, respectively.

\begin{tabular}{lcccccc}
\hline \multirow{2}{*}{ Parameter } & \multicolumn{2}{c}{2017 season } & \multicolumn{2}{c}{2018 season } & \multicolumn{2}{c}{ Overall } \\
& Mean \pm SD & $N$ & Mean \pm SD & $N$ & Mean \pm SD & $N$ \\
\hline $\begin{array}{l}\text { Clutch size } \\
\text { Nesting success }\end{array}$ & 8 eggs \pm 3 & 7 & 7 eggs \pm 1 & 10 & 8 eggs \pm 2 & 17 \\
$\begin{array}{l}\text { Incubation } \\
\text { days }\end{array}$ & 95 days \pm 4 & 6 & 98 days \pm 5 & 9 & 97 days \pm 5 & 15 \\
\hline
\end{tabular}

the second clutch on $31^{\text {st }}$ December 1986 [23]. It worth mentioning that the first clutch failed and the female was not with hatchlings at the time the second clutch was laid. It is not known whether parenting hatchlings influence the nesting frequency of dwarf crocodiles. If it is the case, then it is likely that the nesting frequency of dwarf crocodiles in captivity will differ from those in the wild, because in captivity, hatchlings are often seperated from females.

Apart from the wild population study by Waitkuwait [7], there has been a couple of studies on the clutch size of West African dwarf crocodiles in captivity. Hara and Kikuchi [34] conducted a study at the Ueno Zoo and reported a mean clutch value of $\sim 13$ eggs. Becks [32] found a mean value of 14 eggs at the Memphis Zoo. Tyron [30] conducted similar studies at the Fort Worth Zoo and found a mean value clutch of $\sim 13$ eggs. Before these studies, Greer [35] conducted a comparative study on the clutch sizes of 19 crocodilians and 
TABle 4: Hatching success of West African dwarf crocodiles across two nesting seasons (2017 and 2018) in the Chirehin Community Land.

\begin{tabular}{|c|c|c|c|c|c|c|c|}
\hline \multicolumn{4}{|c|}{2017 nesting season } & \multicolumn{4}{|c|}{2018 nesting season } \\
\hline Nest number & Clutch size & Number hatched & Hatching \% & Nest number & Clutch size & Number hatched & Hatching \% \\
\hline 1 & - & 0 & 0 & 1 & 7 & 7 & 100 \\
\hline 2 & 7 & 7 & 100 & 2 & 8 & 8 & 100 \\
\hline 3 & 8 & 8 & 100 & 3 & 7 & 7 & 100 \\
\hline 4 & 13 & 12 & 92 & 4 & 8 & 0 & 0 \\
\hline 5 & 6 & 6 & 100 & 5 & 7 & 7 & 100 \\
\hline 6 & 8 & 7 & 87.5 & 6 & 8 & 6 & 75 \\
\hline 7 & 5 & 0 & 0 & 7 & 8 & 8 & 100 \\
\hline \multirow[t]{3}{*}{8} & 8 & 8 & 100 & 8 & 7 & 0 & 0 \\
\hline & & & & 9 & 7 & 7 & 100 \\
\hline & & & & 10 & 6 & 6 & 100 \\
\hline Total/average & 55 eggs & 48 eggs & $72.4 \pm 44.9$ & & 73 & 56 & $77.5 \pm 41.6$ \\
\hline
\end{tabular}

TABLE 5: The viability of West African dwarf crocodile eggs recorded across two nesting seasons (2017 and 2018) in the Chirehin Community Land, Ghana.

\begin{tabular}{|c|c|c|c|c|c|c|c|}
\hline \multicolumn{4}{|c|}{2017 nesting season } & \multicolumn{4}{|c|}{2018 nesting season } \\
\hline Nest number & Clutch size & Number viable & Viability \% & Nest number & Clutch size & Number viable & Viability \% \\
\hline 1 & - & - & - & 1 & 7 & 7 & 100 \\
\hline 2 & 7 & 7 & 100 & 2 & 8 & 8 & 100 \\
\hline 3 & 8 & 8 & 100 & 3 & 7 & 7 & 100 \\
\hline 4 & 13 & 13 & 100 & 4 & 8 & 0 & 0 \\
\hline 5 & 6 & 6 & 100 & 5 & 7 & 7 & 100 \\
\hline 6 & 8 & 7 & 87.5 & 6 & 8 & 8 & 100 \\
\hline 7 & 5 & 0 & 0 & 7 & 8 & 8 & 100 \\
\hline \multirow[t]{3}{*}{8} & 8 & 8 & 100 & 8 & 7 & 7 & 100 \\
\hline & & & & 9 & 7 & 7 & 100 \\
\hline & & & & 10 & 6 & 6 & 100 \\
\hline Total/average & 55 eggs & 49 & $83.9 \pm 37.3$ & & 73 & 65 & $90 \pm 31.6$ \\
\hline
\end{tabular}

TABle 6: Clutch attributes of West African dwarf crocodile in Chirehin Community Land (2017). SD and N represent standard deviations and the total number of recordings used for the calculations, respectively.

\begin{tabular}{lccc}
\hline & Egg mass (g) & Egg width $(\mathrm{mm})$ & Egg length $(\mathrm{mm})$ \\
\hline Mean \pm SD & $66.1 \pm 4.9$ & $38.3 \pm 1.1$ & $69.9 \pm 2.4$ \\
Range & $50-75$ & $36-40$ & $66-74$ \\
$\mathrm{~N}$ & 28 & 28 & 28 \\
\hline
\end{tabular}

concluded that dwarf crocodile has the smallest clutch size reporting an average of 6 eggs. There is variation in the reported mean clutch size of dwarf crocodiles with available records ranging from 6 to 14 eggs. This variance is likely to have been influenced by the source of the nests (from the wild or captivity), size of female, and the limited number of studies available. To provide a more precise estimate of the mean clutch size of dwarf crocodiles there is a need to treat wild populations and captive populations discretely. Another factor that is affecting the precision of dwarf crocodiles clutch size estimate is the sample size. Most of the existing literature used less than five nests in their analyses and this usually results in large standard deviations.

Regardless of the variations in literature, all authors reported small clutch sizes relative to other crocodilians. Therefore, the potential recruitment to the adult population is limited for this species, which can influence population growth and resilience. Developing a sustainable harvesting model for the species will require a thorough understanding of how the clutch size and other factors such as nesting success, hatchling survival interact to influence population dynamics. Unfortunately, no such management models exist throughout the species' range and hunting is mostly unregulated. Kofron [9] reported that Liberia which was believed to be the stronghold for West African dwarf crocodiles, now having a depleted population with scattered individuals mainly because of unregulated hunting. A similar observation has been made in Ghana from recent studies (E. Amoah, unpublished data)

4.4. Nesting and Hatching Success of Dwarf Crocodiles in Chirehin. Findings from this study suggest that dwarf crocodiles in the Chirehin Community Land start nesting at the end of the dry season which is around late March to early June and hatching occurs from mid-June to late August. It is at this period that materials are in abundance for nest construction and also beginning of the rainy season favours the decomposition of the vegetative materials which facilitate the generation of heat during incubation. The result is congruent with what was observed in a neighbouring 

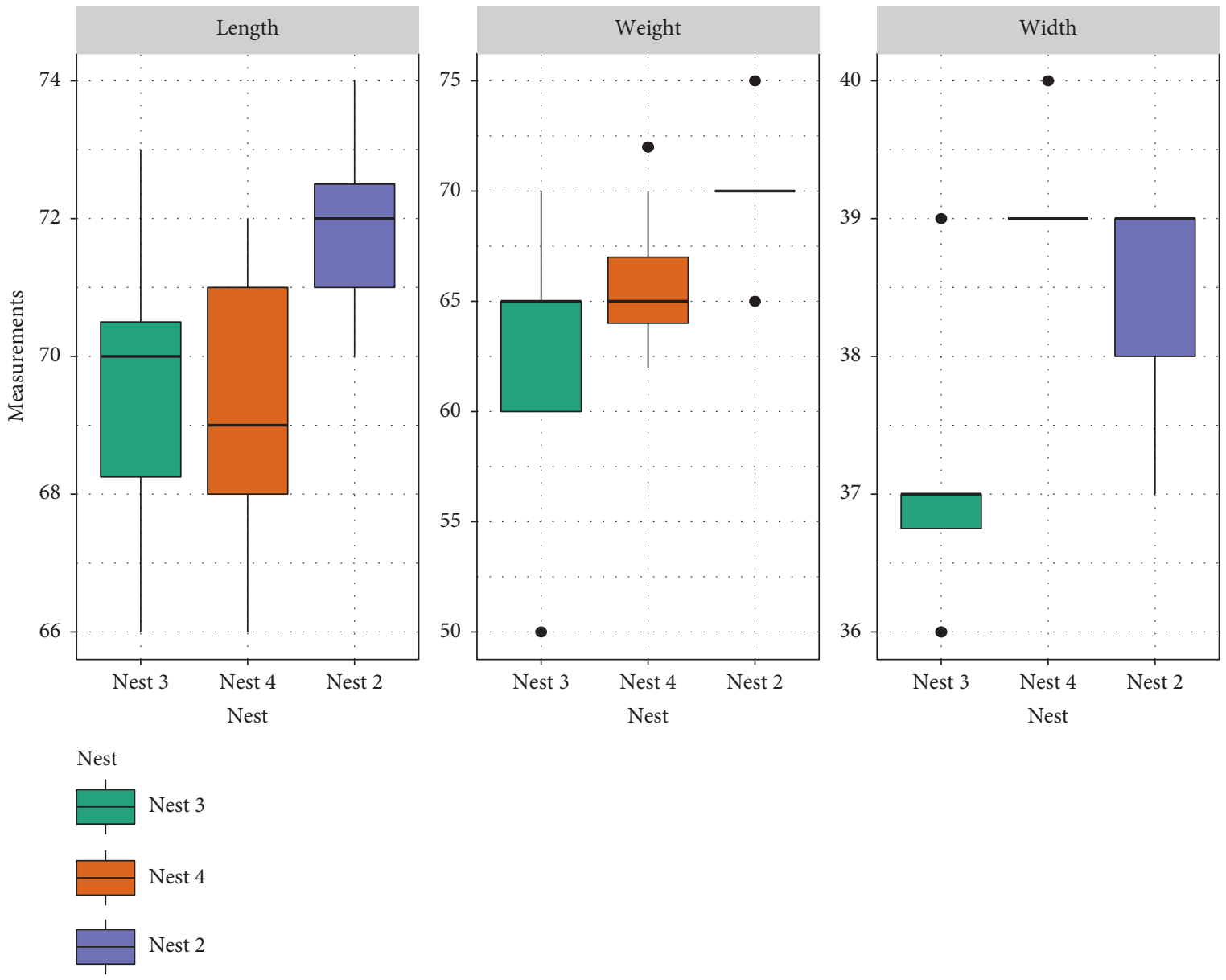

Figure 7: Comparison of means of egg measurements among three nests.

country, Côte d'Ivoire by Waitkuwait [7]. The average incubation period of $\sim 100$ days is also consistent with data published by Waitkuwait [7] who estimated 100 days. No attempt has been made to compare the captive incubation days to this result as laboratory conditions vary from the natural settings.

Having been recognized as one of the least fecund among all the extant crocodilians in terms of clutch size, it will be interesting to know the proportion of dwarf crocodile clutches that successfully go through incubation to hatching. With nesting success of 75\% and $80 \%$ for 2017 and 2018 nesting season, respectively, and overall nesting success of $\sim 78 \%$, the dwarf crocodiles in Chirehin Community Land appear to face fewer problems with nest failure. Three nests were destroyed by flood and the other by an unknown predator. Although we did not directly observe the egg predation, we suspect it might have been destroyed by a West African Nile monitor lizard (Varanus stellatus) because it is the only known predator of crocodile eggs we have found in the study site so far. We ruled out the possibility of humans poaching the eggs because the species is strictly protected by local traditional beliefs that prohibit its consumption. Furthermore, we found remains of the eggshells which suggest that eggs were eaten in situ. Findings from this study is consistent with previous reports which stated that flood and predation are the major causes of nest failure among mound nesting crocodilians with other factors such as unsustainable thermal regimes playing a negligible role [27, 36-39]. Although at Chirehin Community Land, nesting females mostly selected areas that are not subject to inundation, flood was the most important factor of nest failure. Also, apart from the nest which had all its eggs eaten, no other sign of predation attempt was recorded throughout the study. A possible explanation for the low egg predation that was recorded could be the low population densities of potential predators at the study site [33].

Out of 128 eggs found during the two seasons, $114 \mathrm{had}$ banded at the time nests were opened. According to Ferguson [16], freshly laid crocodilians eggs appear homogeneously white and translucent and within 24 hours of egg-laying; fertile eggs develop a small, opaque, chalky white, oval patch on the top surface of the egg which expands in length and width until the egg is completely opaque. However, infertile eggs remain uniformly translucent white throughout the entire incubation period. The mean egg viability per nest of $\sim 84 \%$ and $~ 90 \%$ for 2017 and 2018, respectively, and overall viability of $\sim 88 \%$ recorded in the Chirehin Community Land were high. With a mean hatching rate per nest of $72 \%$ and $78 \%$ in 2017 and 2018, respectively, and an overall hatching rate of $75 \%$, the hatching success of dwarf crocodiles in 
Chirehin Community Land appeared relatively higher than reported in captivity. Perhaps, in captivity, other confounding factors affect hatching success. For instance, Hara and Kikuchi [34] reported hatching success for breeding at the Ueno Zoo, Tokyo, for the years 1972, 1973, and 1975 as $33.5 \%$, $46.1 \%$, and $37.5 \%$, respectively. It is likely that, in the wild, high nesting success and high egg viability are acting as a balance against African's diminutive crocodilian reported small clutch size.

\section{Conclusions}

The study has provided the most comprehensive data on the nesting ecology of the wild population of West African dwarf crocodiles to date with 18 nests from two seasons. The findings from this study support earlier reports on dwarf crocodiles as the least fecund among the extant crocodilians. However, it appears that the combination of high fertility, nesting success, and good hatch success offsets the low fecundity of this species and may be responsible for its continued survival across a wide range despite significant human disturbance and harvest for food. Nevertheless, there is evidence to suggest where hunting and habitat disturbances have been extreme, local populations have been seriously affected. The study has demonstrated that dwarf crocodile nest temperature fluctuates throughout the incubation period and this is not significantly influenced by the ambient temperature. Efforts should be made to repeat the study across the species' range for an improved understanding of its nesting ecology.

\section{Data Availability}

All the data used to support the findings of this study are available from the corresponding author upon request.

\section{Conflicts of Interest}

The authors declare no conflicts of interest regarding the use of research contents and publication of this paper.

\section{Acknowledgments}

The authors are grateful to the Department of Wildlife and Range Management of Kwame Nkrumah University of Science and Technology for their support throughout this work. They wish to thank Professor Jeffery William Lang for his insightful suggestions on data loggers before the start of this study. They are very grateful to the following: Paul Tehoda, Issah Seidu, Clement Sullibie Saagulo, and John Fohensi Tettey who assisted them during data collection. To the lovely people of Chirehin, especially Nana Owusu Gyan II and his family, the authors say thank you for making them feel at home during the data collection. Special thanks go to Dr. James Perran Ross and Dr. Matthew Harton Shirley for their financial support which made it possible to secure Hobo tibbit data loggers, accessories, and rechargeable batteries for this work. They are thankful to the IUCN-SSC Crocodile Specialist Group for supporting this project through their Student Research Assistance Scheme.

\section{References}

[1] M. J. Eaton, "Dwarf crocodile Osteolaemus tetraspis. Crocodiles," in Status Survey and Conservation Action Plan, pp. 127-132, Crocodile Specialist Group, Darwin, Australia, 2010.

[2] M. H. Shirley, B. Burtner, R. Oslisly, D. Sebag, and O. Testa, "Diet and body condition of cave-dwelling dwarf crocodiles (Osteolaemus tetraspis, Cope 1861) in Gabon," African Journal of Ecology, vol. 55, no. 4, pp. 411-422, 2016.

[3] C. P. Kofron and C. Steiner, "Observations on the african dwarf crocodile, Osteolaemus tetraspis," Copeia, vol. 1994, no. 2, pp. 533-535, 1994.

[4] J. Riley and F. W. Huchzermeyer, "African dwarf crocodiles in the Likouala swamp forests of the Congo Basin: habitat, density, and nesting," Copeia, vol. 1999, no. 2, pp. 313-320, 1999.

[5] J. P. Ross, Crocodiles: Status Survey and Conservation Action Plan, SSC Crocodile Specialist Group, Karama, NT 0813, Australia, 1998.

[6] M. H. Shirley, W. Oduro, and H. Y. Beibro, "Conservation status of crocodiles in Ghana and Côte d'Ivoire, West Africa," Oryx, vol. 43, no. 1, pp. 136-145, 2009.

[7] W. E. Waitkuwait, "Present Knowledge on the West African Slender-Snouted Crocodile and West, Crocodylus Ctataphractus Cuvier 1824 and the West African Dwarf Crocodile, Osteolaemus Tetraspis Cope 1861," in Crocodiles: Their Ecology, Management and Conservation, IUCN, Gland, Switzerland, 1989.

[8] M. J. Eaton, A. Martin, J. Thorbjarnarson, and G. Amato, "Species-level diversification of African dwarf crocodiles (Genus Osteolaemus): a geographic and phylogenetic perspective," Molecular Phylogenetics and Evolution, vol. 50, no. 3, pp. 496-506, 2009.

[9] C. P. Kofron, "Status and habitats of the three African crocodiles in Liberia," Journal of Tropical Ecology, vol. 8, no. 3, pp. 265-273, 1992.

[10] Crocodile Specialist Group, Osteolaemus Tetraspis. The IUCN Red List of Threatened Species 1996, Crocodile Specialist Group, Darwin, Australia, 1996.

[11] United Nation Environment Programme, "World conservation monitoring centre (UNEP-WCMC) checklist of CITES species," United Nation Environment Programme, Nairobi, Kenya, 2013, https://www.unep-wcmc.org/resources-anddata/checklist-of-cites-species.

[12] X. Combrink, J. K. Warner, and C. T. Downs, "Nest-site selection, nesting behaviour and spatial ecology of female Nile crocodiles (Crocodylus niloticus) in South Africa," Behavioural Processes, vol. 135, pp. 101-112, 2017.

[13] S. G. Platt and J. B. Thorbjarnarson, "Nesting ecology of the American crocodile in the coastal zone of Belize," Copeia, vol. 2000, no. 3, pp. 869-873, 2000.

[14] Ghana Statistical Service, "2010 population and housing census report," Ghana Statistical Service, Accra, Ghana, 2014.

[15] P. Charruau, "Microclimate of American crocodile nests in Banco Chinchorro biosphere reserve, Mexico: effect on incubation length, embryos survival and hatchlings sex," Journal of Thermal Biology, vol. 37, no. 1, pp. 6-14, 2012.

[16] M. W. Ferguson, "The structure and composition of the eggshell and embryonic membranes of Alligator mississippiensis," The Transactions of the Zoological Society of London, vol. 36, no. 2, pp. 99-152, 1982. 
[17] A. H. Escobedo-Galván, "Temperature variation in nests of Caiman crocodilus (crocodylia: alligatoridae)," Acta Herpetologica, vol. 1, no. 2, pp. 131-134, 2006.

[18] F. VillamarÍn-Jurado and E. Suárez, "Nesting of the black caiman (Melanosuchus niger) in northeastern Ecuador," Journal of Herpetology, vol. 41, no. 1, pp. 164-167, 2007.

[19] G. J. W. Webb, S. C. Manolis, P. J. Whitehead, and K. Dempsey, "The possible relationship between embryo orientation opaque banding and the dehydration of albumen in crocodile eggs," Copeia, vol. 1987, no. 1, pp. 252-257, 1987.

[20] M. W. J. Ferguson and T. Joanen, "Temperature of egg incubation determines sex in Alligator mississippiensis," Nature, vol. 296, no. 5860, pp. 850-853, 1982.

[21] C. I. Piña, A. Larriera, and M. R. Cabrera, "Effect of incubation temperature on incubation period, sex ratio, hatching success, and survivorship in Caiman latirostris (Crocodylia, Alligatoridae)," Journal of Herpetology, vol. 37, no. 1, pp. 199-202, 2003.

[22] W. E. Magnusson, A. P. Lima, J.-M. Hero, T. M. Sanaiotti, and M. Yamakoshi, "Paleosuchus trigonatus nests: sources of heat and embryo sex ratios," Journal of Herpetology, vol. 24, no. 4, pp. 397-400, 1990.

[23] C. McCartney, "Breeding of west african dwarf crocodiles (Osteolaemus tetraspis tetraspis) at the port Elizabeth Snake Park," The Journal of the Herpetological Association of Africa, vol. 38, no. 1, pp. 44-48, 1990.

[24] D. C. Deeming, "Prevalence of TSD in crocodilians," in Temperature-Dependent Sex Determination in Vertebrate, pp. 33-41, Smithsonian Institute Press, Washington DC, USA, 2004.

[25] J. W. Lang and H. V. Andrews, "Temperature-dependent sex determination in crocodilians," Journal of Experimental Zoology, vol. 270, no. 1, pp. 28-44, 1994.

[26] T. Rhen and J. W. Lang, "Phenotypic effects of incubation temperature in reptiles," in Temperature-Dependent Sex Determination in Vertebrates, pp. 90-98, Smithsonian Institution Press, Washington DC, USA, 2004.

[27] M. A. Ewert and C. E. Nelson, "Metabolic heating of embryos and sex determination in the American alligator, Alligator mississippiensis," Journal of Thermal Biology, vol. 28, no. 2, pp. 159-165, 2003.

[28] A. J. Leslie and J. R. Spotila, "Alien plant threatens Nile crocodile (Crocodylus niloticus) breeding in Lake St. Lucia, South Africa," Biological Conservation, vol. 98, no. 3, pp. 347-355, 2001.

[29] J. Thorbjarnarson, X. Wang, and L. He, "Reproductive ecology of the Chinese alligator (Alligator sinensis) and implications for conservation," Journal of Herpetology, vol. 35, no. 4, pp. 553-558, 2001.

[30] B. W. Tryon, "Observation on the reproduction in the West African dwarf crocodile with a description on parental behaviour," SSAR Contribution to Herpetology No. 1, vol. 1994, pp. 533-535, 1990.

[31] N. Helfenderger, "A contribution to the reproductive biology of Osteolaemus t. tretraspis," Herpetofuana, vol. 11, pp. 9-11, 1981.

[32] C. Beck, "Breeding the West african dwarf crocodile," International Zoo Yearbook, vol. 18, no. 1, pp. 89-91, 1978.

[33] B. A. Shanbhag, R. S. Radder, and S. K. Saidapur, "Maternal size determines clutch mass, whereas breeding timing influences clutch and egg sizes in the tropical lizard, Calotes versicolor (agamidae)," Copeia, vol. 2000, no. 4, pp. 1062-1067, 2000.
[34] K. Hara and F. Kikuchi, "Breeding the West african dwarf crocodile," International Zoo Yearbook, vol. 18, no. 1, pp. 84-87, 1978.

[35] A. E. Greer, "Clutch size in crocodilians," Journal of Herpetology, vol. 9, no. 3, pp. 319-322, 1975.

[36] J. Allsteadt, "Nesting ecology of Caiman crocodilus in cano negro, Costa Rica," Journal of Herpetology, vol. 28, no. 1, pp. 12-19, 1994.

[37] Z. Campos, "Effect of habitat on survival of eggs and sex ratio of hatchlings of Caiman crocodilus yacare in the pantanal, Brazil," Journal of Herpetology, vol. 27, no. 2, pp. 127-132, 1993.

[38] R. H. Hunt and J. J. Ogden, "Selected aspects of the nesting ecology of American alligators in the Okefenokee Swamp," Journal of Herpetology, vol. 25, no. 4, pp. 448-453, 1991.

[39] S. G. Platt, T. R. Rainwater, J. B. Thorbjarnarson, and S. T. Mcmurry, "Reproductive dynamics of a tropical freshwater crocodilian: morelet's crocodile in northern Belize," Journal of Zoology, vol. 275, no. 2, pp. 177-189, 2008. 